\title{
Clinicopathological Stratification and Long-term Follow-up of Patients with Periampullary Carcinomas
}

\author{
ROSA B. SCHMUCK ${ }^{1}$, CHRISTIAN BROKAT ${ }^{1}$, ANDREAS ANDREOU ${ }^{1}$, MATTHÄUS FELSENSTEIN ${ }^{1,2}$, \\ FRITZ KLEIN $^{1}$, BRUNO SINN ${ }^{3}$, JOHANN PRATSCHKE ${ }^{1}$ and MARCUS BAHRA ${ }^{1}$ \\ Departments of ${ }^{1}$ Surgery, and ${ }^{3}$ Pathology, Charité University of Medicine Berlin, Berlin, Germany; \\ ${ }^{2}$ Department of Pathology, Sol Goldman Pancreatic Cancer Research Center, \\ Johns Hopkins University School of Medicine, Baltimore, MD, U.S.A.
}

\begin{abstract}
Background: Periampullary carcinomas generally confer a poor outcome. Choosing the most effective treatment regimen for each sub-entity proves challenging and is usually based on experience from pancreatic adenocarcinoma (PDAC). Patients and Methods: The long-term follow-up is presented of 472 patients with periampullary tumors [PDAC, distal cholangiocarcinoma $(d C C)$ and ampullary carcinomas (AC)] who underwent radical resection considering clinical characteristics, paraclinical findings and histopathological features in order to define factors of prognostic relevance. Results: Patients with PDACs presented with larger tumor sizes, more frequent $R 1$ resection, higher rate of nodal and perineural invasion, higher tumor stage according to the classification of tumors of the Union Internationale contre le Cancer when compared to those with dCCs and ACs. In a multivariate analysis, age >65 years, postoperative complications and higher grading of the tumor proved to be independent prognostic factors for survival. Conclusion: Patients suffering from PDAC have the worst prognosis and greatest benefit from radical resection of all patients with periampullary tumors. More detailed studies are warranted to better distinguish between the different entities.
\end{abstract}

The family of periampullary carcinomas comprises adenocarcinomas originating from the pancreatic head (PDAC), the distal bile duct (dCC), the periampullary duodenum and carcinomas of the ampulla of Vater (AC; Figure 1) (1). Due to their close anatomic vicinity and

Correspondence to: Dr. med. Rosa B. Schmuck, Chirurgische Klinik Charité - Universitätsmedizin Berlin, Augustenburger Platz 1, 13353 Berlin, Germany. Tel: +49 30450652184, Fax: +49 304507652184, e-mail: rosa.schmuck@charite.de

Key Words: Periampullary carcinomas, pancreatic cancer, cholangiocarcinoma, ampullary carcinomas. molecular similarities, the final diagnosis sometimes remains undetermined (2). Therefore, choosing the most effective therapeutic regimen for each given entity proves problematic. However, the clinical significance of histopathological patterns such as lymph-node (LN) and perineural or lymphatic vessel involvement may differ among periampullary tumor entities and can notably influence the clinical course.

The most frequent carcinomas of the periampullary region are PDACs, accounting for up to $70 \%$ of all tumors, whilst $\mathrm{dCC}$ and $\mathrm{AC}$ make up 10-20\% and duodenal carcinomas $3-7 \%(3,4)$. While PDACs are associated with the poorest outcome, with 5-year survival rates of $15-20 \%$ after resection with curative intent (3-6), rates of $\mathrm{dCC}$ and $\mathrm{AC}$ are considerably better at $20-30 \%$ and $40 \%$, respectively $(4,7-9)$.

The most relevant histopathological subclassification of periampullary carcinomas distinguishes between an intestinal type and a more aggressive pancreaticobiliary type $(10,11)$. Sequencing attempts further evaluated distinct genomic signatures in (peri-) ampullary cancer and revealed various differences, at least between the intestinal and pancreatobiliary types $(12,13)$. However, molecular signatures which distinguish between periampullary entities have not yet been evaluated. Therefore, we still have to rely on pathological assessments and their anatomical relationship with the biliopancreatic duct system.

In contrast to the adjuvant treatment of PDACs, no standard regimen for $\mathrm{AC}$ and $\mathrm{dCC}$ has been established due to a lack of data (14). The only curative treatment of all tumor subentities is based on radical resection of the entire tumor burden (R0). Recently, neoadjuvant therapy approaches have been implemented into clinical practice for PDAC. Neoadjuvant chemotherapy can be taken into account for patients presenting with borderline resectable tumors or for patients with a resectable tumor but additional high-risk features (15). Current regimens include FOLFIRINOX (folinic acid, fluorouracil, irinotecan hydrochloride and oxaliplatin), and the combination of gemcitabine and nab-paclitaxel (16). For dCC 

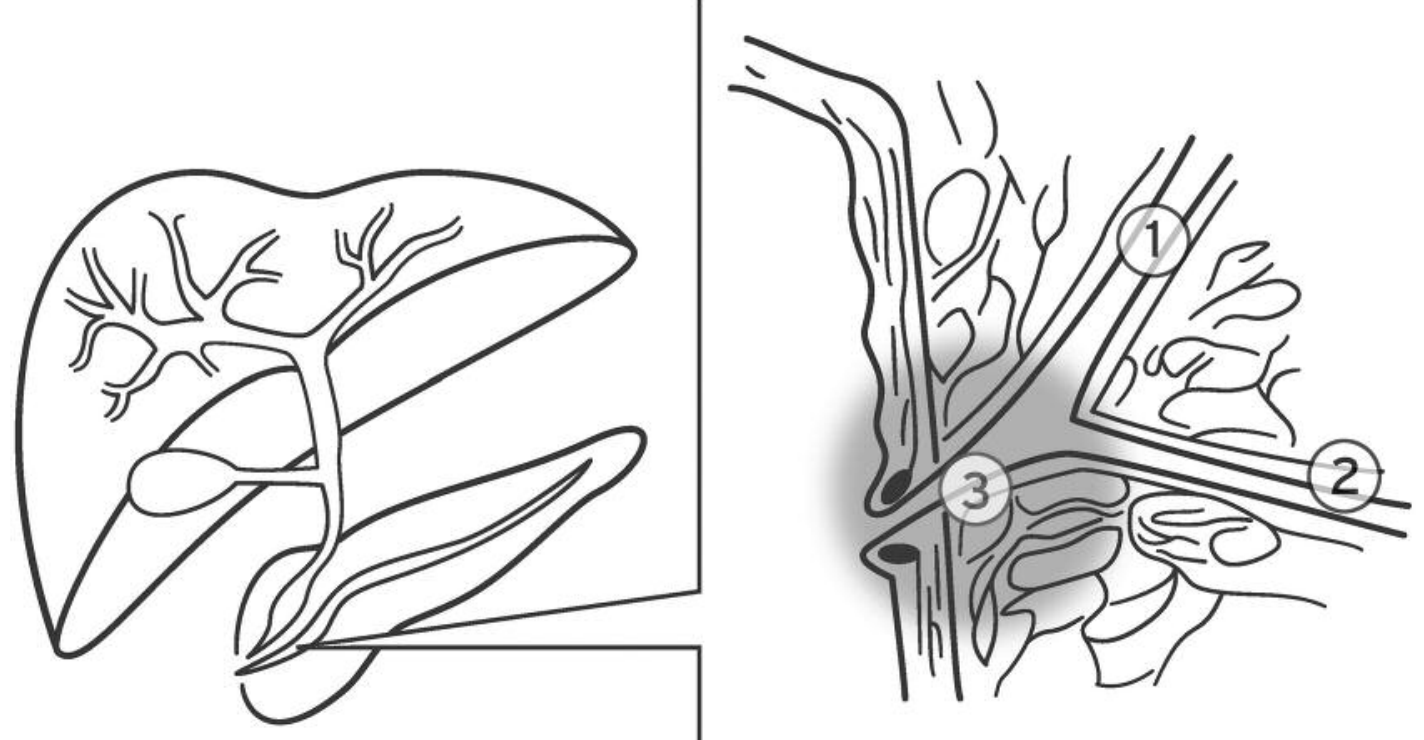

Figure 1. Anatomical location and structure of the periampullary region including the distal bile duct (\#1), the pancreatic duct (\#2) and the periampullary region (\#3).

and $\mathrm{AC}$, data on the efficacy of neoadjuvant treatment are lacking.

In this retrospective study, the data of 472 patients suffering from periampullary carcinomas who underwent radical resection were analyzed considering clinical characteristics, paraclinical findings and histopathological features in order to define factors of prognostic relevance. The primary purpose of this study was to analyze variables influencing perioperative morbidity and long-term survival of the different study cohorts in periampullary carcinoma. Defining patients with the greatest benefit from surgery would have substantial impact on the quality of treatment.

\section{Patients and Methods}

Patients and data acquisition. Patients who underwent resection of a tumor in close proximity (up to $2 \mathrm{~cm}$ ) to the ampulla of Vater were included in the study. Clinical and paraclinical data of patient, treatment and tumor characteristics were collected in a database. Procedures were in accordance with the ethical standards of the responsible committee on human experimentation, following approval from the Institutional Review Board (EA1/292, EA2/035) and in accordance with the Helsinki Declaration of 1975.

Preoperative assessment. Preoperative evaluation included laboratory values, medical history, imaging results, previous treatment, cardiac and pulmonary function tests and anesthesia evaluation. Diagnosis and preoperative staging of periampullary cancer was based on computed tomography (CT) or magnetic resonance imaging (MRI), sometimes accompanied by endoscopic retrograde cholangiopancreatography, diagnostic laparoscopy and fluorodeoxyglucose positron-emission tomography. Treatment was decided by a multidisciplinary tumor board. None of the patients received neoadjuvant treatment.

Surgical technique and postoperative treatment. All resections were performed as pylorus-preserving pancreaticoduodenectomy (PPPD) or Kausch-Whipple procedure as described elsewhere $(17,18)$. The anastomosis of the pancreatic remnant was performed either as pancreatogastrostomy or pancreatojejunostomy. The biliodigestive continuity was reconstructed by an anastomosis of the common bile duct and a jejunal loop with a Roux-en-Y gastrojejunostomy. Adjuvant treatment was decided by multidisciplinary institutional tumor board and initiated within 6 weeks following operation.

Postoperative assessment. Postoperative survival was defined as starting from the day of resection of the tumor to the day of last follow-up, and postoperative mortality as death within 30 days after the operation. Postoperative morbidity was defined as occurrence of complications (including anastomotic leak, pancreatic fistula, bleeding, intra-abdominal infection, and organ failure) within 30 days after the operation. Postoperative fistulas were classified according to Bassi et al. (19).

Histological evaluation. Histopathological assessment was carried out by a senior physician specialized in pathology of the pancreas and bile duct. Tumors were classified according to the TNM classification of the Union Internationale contre le Cancer (UICC) classification of tumors (20).

Statistical analysis. For statistical analysis, SPSS (version 16 and 22; IBM Corp., Armonk, New York, USA) was used. The 
Table I. Operation characteristics of patients suffering from adenocarcinomas originating from the pancreatic head (PDAC), the distal bile duct $(d C C)$, and carcinomas of the ampulla of Vater $(A C)$.

\begin{tabular}{|c|c|c|c|c|c|c|}
\hline Characteristic & & $\mathrm{n}$ & PDAC & $\mathrm{AC}$ & $\mathrm{dCC}$ & $p$-Value \\
\hline \multirow[t]{3}{*}{ Operation } & PPPD & 284 & 135 & 95 & 54 & $0.015^{\ddagger}$ \\
\hline & Kausch-Whipple & 176 & 108 & 42 & 26 & \\
\hline & $p$-Value $\ddagger$ & & $0.008 v s . \mathrm{AC}$ & 0.778 vs. $\mathrm{dCC}$ & $0.060 v s$. PDAC & \\
\hline \multirow[t]{3}{*}{ Duration (min) } & Median & 464 & 350 & 315 & 330 & $<0.001^{*}$ \\
\hline & Min-Max & & $190-720$ & $182-785$ & $230-710$ & \\
\hline & $p$-Value ${ }^{\dagger}$ & & $<0.001 v s . \mathrm{AC}$ & 0.312 vs. $\mathrm{dCC}$ & 0.022 vs. PDAC & \\
\hline \multirow[t]{2}{*}{ Blood loss (ml) } & Median & 298 & 625 & 500 & 600 & $0.417 *$ \\
\hline & Min-Max & & $100-5000$ & $100-17000$ & $100-2000$ & \\
\hline \multirow[t]{2}{*}{ Intraoperative complications } & Yes & 36 & 22 & 10 & 4 & $0.307^{\ddagger}$ \\
\hline & No & 417 & 225 & 118 & 74 & \\
\hline \multirow[t]{2}{*}{ Postoperative complications } & Yes & 178 & 89 & 50 & 39 & $0.282^{\ddagger}$ \\
\hline & No & 277 & 160 & 76 & 41 & \\
\hline \multirow[t]{2}{*}{ Perioperative lethality } & Yes & 11 & 1 & 6 & 4 & $0.187^{\ddagger}$ \\
\hline & No & 461 & 250 & 135 & 76 & \\
\hline \multirow[t]{2}{*}{ Operative revision } & Yes & 69 & 34 & 18 & 17 & $0.449^{*}$ \\
\hline & No & 385 & 215 & 108 & 62 & \\
\hline \multirow[t]{2}{*}{ ICU stay (days) } & Median & 396 & 3 & 3 & 3 & $0.988^{*}$ \\
\hline & Min-Max & & $1-76$ & $1-124$ & $1-63$ & \\
\hline \multirow[t]{2}{*}{ Hospital stay (days) } & Median & 445 & 16 & 16 & 18 & $0.202 *$ \\
\hline & Min-Max & & $10-356$ & $10-100$ & $7-125$ & \\
\hline
\end{tabular}

ICU: Intensive Care Unit; PPPD: pylorus-preserving pancreaticoduodenectomy. ${ }^{\ddagger}$ Chi-square test, $*$ Kruskal-Wallis test, ${ }^{\dagger}$ Mann-Whitney $U$-test.

distribution of variables was arithmetically averaged. In the case of missing values, the relative frequency referred to the data available unless indicated otherwise. The D'Agostino and Pearson omnibus normality test was used to test for normal distribution of data. When two variables (numeric and categorical or numeric and numeric) between two groups were compared, Student's $t$-test was applied for normally distributed data and the Mann-Whitney $U$-test in the case of non-normally distributed data. For comparison of two categorical variables, the Chi-square test was applied. When comparing more than two groups, analysis of variance (ANOVA) was implemented for normally distributed data and Kruskal-Wallis for not normally distributed data. To describe cumulative survival, the Kaplan-Meier method was used. Paired comparison between the tumor entities was calculated using Bonferroni corrected log-rank (Mantel-Cox) test. Cut-off levels were identified using the Youden Index, where the maximum value of the index was used to identify the ideal cut-off point based on receiver operating characteristics curve (ROC). Sensitivity and specificity were calculated with a confusion matrix of binary classification. A logistic regression model was applied to evaluate the effect of positive LNs on survival. A $p$-value of 0.05 or less was considered to be significant. Variables showing a significant effect on survival were included in multivariate analysis.

\section{Results}

Surgical characteristics. Patients underwent either a PPPD, or a Kausch-Whipple procedure (284vs. 176; $p=0.015)$. The duration of surgery was longest in patients suffering from PDAC compared to those with AC or dCC $(p<0.001$ and $p=0.022$, respectively). There were no significant differences regards blood loss, intraoperative or postoperative complications, perioperative mortality, need for surgical revision, intensive care unit and hospital stay between the three tumor entities (Table I).

Patient characteristics. In $53.2 \%$ of the patients (251/472), a PDAC was diagnosed, whereas $29.9 \%$ (141/472) of the patients had an AC and $16.9 \%$ (80/472) were diagnosed with dCC. There were no significant differences with regard to gender, age, pre-existing illness, alcohol or nicotine abuse or family history of malignant diseases. Body mass index was significantly higher in patients suffering from PDAC ( $p=0.004$; Table II).

Tumor characteristics. Comparing disease extent of periampullary entities, significant differences were found between the groups regarding $\mathrm{T}$ (tumor size) and $\mathrm{N}(\mathrm{LN})$ classification, and UICC staging $(p<0.001)$. dCCs were found to be smaller in size as well as having a lower T-stage when compared to ACs and PDACs. Tumors in patients suffering from PDAC were of a significantly higher UICC stage than in both patients with $\mathrm{dCC}(p<0.001)$ and those with AC ( $p=0.001)$. When comparing AC and $\mathrm{dCC}$, patients suffering from dCC presented with higher UICC stage at surgery than those with AC $(p<0.001)$. Higher-staged disease resulted in a higher frequency of positive resection margins. There were no differences between the groups regards tumor grading and metastasis (Table III). 
Table II. Characteristics of patients suffering from adenocarcinomas originating from the pancreatic head (PDAC), the distal bile duct (dCC), and carcinomas of the ampulla of Vater $(A C)$.

\begin{tabular}{|c|c|c|c|c|c|c|}
\hline Characteristic & & $\mathrm{n}$ & PDAC & $\mathrm{AC}$ & $\mathrm{dCC}$ & $p$-Value \\
\hline \multirow[t]{2}{*}{ Sex } & Male & 282 & 146 & 83 & 53 & $0.425 \neq$ \\
\hline & Female & 190 & 105 & 58 & 27 & \\
\hline \multirow[t]{2}{*}{ Age, years } & Median & 472 & 65 & 65 & 67 & $0.385 *$ \\
\hline & Min-Max & & $37-87$ & $34-83$ & $39-89$ & \\
\hline \multirow[t]{3}{*}{ BMI, $\mathrm{kg} / \mathrm{m}^{2}$} & Median & 437 & 25.2 & 24.6 & 23.8 & $0.004 *$ \\
\hline & Min-Max & & $14.8-49.3$ & $13.6-38.9$ & $13.6-35.2$ & \\
\hline & $p$-Value ${ }^{\dagger}$ & & $0.057 v s . \mathrm{AC}$ & $0.418 v s . \mathrm{dCC}$ & $0.005 v s$. PDAC & \\
\hline \multirow[t]{2}{*}{ Pre-existing illness } & Yes & 385 & 212 & 104 & 69 & $0.125^{\ddagger}$ \\
\hline & No & 70 & 38 & 21 & 11 & \\
\hline \multirow[t]{2}{*}{ Alcohol } & Yes & 114 & 65 & 33 & 16 & $0.871^{\ddagger}$ \\
\hline & No & 323 & 173 & 91 & 59 & \\
\hline \multirow[t]{2}{*}{ Nicotine } & Yes & 177 & 108 & 44 & 25 & $0.257 \ddagger$ \\
\hline & No & 267 & 135 & 80 & 52 & \\
\hline \multirow{2}{*}{ Family history } & Positive & 32 & 19 & 7 & 6 & $0.317^{\ddagger}$ \\
\hline & Negative & 117 & 55 & 36 & 26 & \\
\hline \multirow[t]{3}{*}{ Preoperative CA 19-9 } & Median & 336 & 158 & 23 & 67 & $<0.001^{*}$ \\
\hline & Min-Max & & $1-93929$ & $1-9171$ & $1-13084$ & \\
\hline & $p$-Value ${ }^{\dagger}$ & & $<0.001$ vs. AC & $0.01 v s . \mathrm{dCC}$ & $0.001 v s$. PDAC & \\
\hline \multirow[t]{3}{*}{ Preoperative CEA } & Median & 318 & 2.8 & 1.4 & 2.1 & $<0.001 *$ \\
\hline & Min-Max & & $0.0-36.0$ & $0.2-9.4$ & $0.5-16.5$ & \\
\hline & $p$-Value ${ }^{\dagger}$ & & $<0.001 v s . \mathrm{AC}$ & 0.037 vs. $\mathrm{dCC}$ & $0.013 v s$. PDAC & \\
\hline
\end{tabular}

BMI: Body mass index; CEA: carcinoembryonic antigen; CA 19-9: carbohydrate antigen. ${ }^{\ddagger}$ Chi-square test, *Kruskal-Wallis test, ${ }^{\dagger}$ Mann-Whitney $U$-test.

LN metastasis. Patients with PDAC were more often diagnosed with nodal-positive disease compared to patients with AC or $\mathrm{dCC}(p<0.001$ and $p=0.003$; Table I). Comparing the total number of positive LNs, LNs removed, and the resulting $\mathrm{LN}$ ratio (LNR), no significant differences were found between the tumor entities. Focusing on the correlation between T-stage and LNR, for all entities, a strong correlation between a higher T-stage and a higher LNR $(p=0.006)$ was found.

Perineural infiltration. PDAC had the highest rate of perineural invasion (91.4\%) compared to $\mathrm{dCC}(88.1 \%)$ and $\mathrm{AC}(61.3 \%)$ considering all cases with available perineural assessment $(p=0.032)$. As we had very few cases with histologicallyproven negative perineural invasion, the analysis was repeated comparing positive cases with all other cases and still found PDAC to have the highest rate of perineural infiltration $(59.4 \%$ vs. $54.8 \%$ vs. $14.5 \%$, respectively).

Tumor markers carcinoembryonic antigen (CEA) and carbohydrate antigen (CA 19-9). Measurement of tumor markers CA 19-9 and CEA before surgery showed significant differences between the three entities. PDAC displayed the highest levels of both markers, followed by $\mathrm{dCC}$ and $\mathrm{AC}$. Differences were also significant when compared pairwise (Table II).
CEA discriminated between $\mathrm{dCC}$ and PDAC $(p=0.041)$ with a threshold of $5 \mu \mathrm{g} / 1$ difference (specificity $94 \%$, sensitivity 25\%). For CA 19-9, specificity (40\%) and sensitivity $(80 \%)$ in regard to discrimination between PDAC and $\mathrm{AC}$ was low. Both CEA and CA 19-9 differentiated reliably between PDAC and AC (CEA: $p<0.001$; CA19-9: $p=0.025$ ), while a high specificity of $92 \%$ with a sensitivity of $75 \%$ was achieved when both markers were combined.

Survival analysis. The median survival of all 472 patients was 21.2 months, the 1 -year survival rate was $66.2 \%$. The overall 5-year survival rate was $26.3 \%$. Patients with PDAC had the poorest median survival (17.2 months) followed by dCC (19.9 months; Figure 2). Patients with AC exhibited the most favorable prognosis (31.9 months) and survived significantly longer than patients with PDAC $(p<0.001)$. However, there was no significant difference in survival rates between patients with $\mathrm{dCC}$ and AC. The T-stage $(p=0.003)$ as well as the $\mathrm{N}$-stage $(p<0.001)$ and metastasis $(\mathrm{M})$ stage $(p=0.001)$ had a significant effect on overall survival. Tumor grading $(p<0.001)$ and the status of the resection margin (R0 vs. R1) also significant influenced survival. In general, patients with a higher UICC stage had a significantly poorer survival rate $(p<0.001$; Table IV).

Looking into technical aspects, longer duration of surgery $(p=0.001)$, greater blood loss $(p<0.001)$ and longer stay in 
Table III. Tumor characteristics of adenocarcinomas originating from the pancreatic head (PDAC), the distal bile duct (dCC), and carcinomas of the ampulla of Vater $(A C)$.

\begin{tabular}{|c|c|c|c|c|c|c|}
\hline Tumor characteristics & & $\mathrm{n}$ & PDAC & $\mathrm{AC}$ & $\mathrm{dCC}$ & $p$-Value \\
\hline \multirow[t]{3}{*}{ Tumor size $(\mathrm{cm})$} & Median & 369 & 3 & 2 & 2 & $<0.001^{*}$ \\
\hline & Min-Max & & $1-8$ & $1-8$ & $1-6$ & \\
\hline & $p$-Value ${ }^{\dagger}$ & & $<0.001 v s . \mathrm{AC}$ & $<0.001 v s . \mathrm{dCC}$ & $<0.001 v s$. PDAC & \\
\hline \multirow{5}{*}{ T-Stage } & $\mathrm{T} 1$ & 18 & 1 & 14 & 3 & $<0.001^{\ddagger}$ \\
\hline & $\mathrm{T} 2$ & 65 & 7 & 47 & 11 & \\
\hline & $\mathrm{T} 3$ & 354 & 243 & 53 & 58 & \\
\hline & $\mathrm{T} 4$ & 34 & 0 & 26 & 8 & \\
\hline & $p$-Value $\ddagger$ & & $<0.001 v s . \mathrm{AC}$ & $<0.001 v s . \mathrm{dCC}$ & $<0.001 \mathrm{vs.}$ PDAC & \\
\hline \multirow[t]{3}{*}{$\mathrm{N}$-Stage } & No & 161 & 60 & 67 & 34 & $<0.001^{\ddagger}$ \\
\hline & N1 & 309 & 190 & 74 & 45 & \\
\hline & $p$-Value $\ddagger$ & & $<0.001 v s . \mathrm{AC}$ & 0.337 vs. dCC & 0.003 vs. PDAC & \\
\hline \multirow[t]{2}{*}{ M-Stage } & M0 & 364 & 186 & 112 & 66 & $0.603 \ddagger$ \\
\hline & M1 & 27 & 14 & 8 & 5 & \\
\hline \multirow{4}{*}{ Resection } & R0 & 367 & 179 & 122 & 66 & $<0.001^{\ddagger}$ \\
\hline & $\mathrm{R} 1$ & 70 & 55 & 4 & 11 & \\
\hline & $\mathrm{R} 2$ & 15 & 10 & 3 & 2 & \\
\hline & $p$-Value $\ddagger$ & & $<0.001 v s . \mathrm{AC}$ & $0.008 v s . \mathrm{dCC}$ & $0.128 v s$. PDAC & \\
\hline \multirow[t]{3}{*}{ Grade } & G1 & 22 & 8 & 10 & 4 & $0.137 \ddagger$ \\
\hline & $\mathrm{G} 2$ & 251 & 126 & 77 & 48 & \\
\hline & G3 & 194 & 116 & 51 & 27 & \\
\hline \multirow[t]{2}{*}{ PerineuraI invasion } & Pn0 & 30 & 13 & 5 & 12 & $0.093 \ddagger$ \\
\hline & Pn1 & 198 & 139 & 40 & 19 & \\
\hline \multirow{7}{*}{ UICC stage } & $1 \mathrm{a}$ & 16 & 1 & 12 & 3 & $<0.001$ \# \\
\hline & $1 \mathrm{~b}$ & 34 & 2 & 27 & 5 & \\
\hline & $2 \mathrm{a}$ & 77 & 42 & 14 & 21 & \\
\hline & $2 b$ & 215 & 141 & 43 & 31 & \\
\hline & 3 & 19 & 0 & 14 & 5 & \\
\hline & 4 & 28 & 15 & 8 & 5 & \\
\hline & $p$-Value $\ddagger$ & & $<0.001 v s . \mathrm{AC}$ & $0.013 v s . \mathrm{dCC}$ & $<0.001 \mathrm{vs.}$ PDAC & \\
\hline
\end{tabular}

${ }^{\ddagger}$ Chi-square test, *Kruskal-Wallis test, ${ }^{\dagger}$ Mann-Whitney $U$-test.

the intensive care unit $(p=0.010)$ resulted in a diminished overall survival. Whereas postoperative complications and the need for operative revisions $(p=0.001)$ had a negative effect on survival $(p=0.020)$, intraoperative complications and duration of hospital stay did not have any significant effect (Table IV).

Only in dCC were we able to find an impact of perineural invasion on survival. This difference was significant when cases with positive perineural infiltration were compared to all cases with $\mathrm{dCC}(p=0.009)$. In PDAC and AC, perineural invasion showed no correlation to patient survival.

We further analyzed the variables LN status, number of positive LNs and LNR separately and discovered an effect on overall survival. In a logistic regression analysis of positive LNs, with each increase of positive LN number, the chance of survival decreased by $25 \%$ (odds ratio $=0.075$, $p=0.002)$. With an increase of the LNR by $10 \%$, the chance of survival decreased by $31 \%$ (odds ratio $=69, p=0.001$ ).

Both preoperative CA 19-9 $(p<0.001)$ and CEA were $(p<0.001)$ predictive for overall survival when including all three entities in the analysis (Table IV). An increase of CEA of $1 \mu \mathrm{g} / \mathrm{l}$ resulted in a decrease of overall survival of $33 \%$.

In multivariate analysis, age older than 65 years (hazard ratio $=1.031,95 \%$ confidence interval $=1.009-1.053$, $p=0.005$ ), postoperative complications (hazard ratio $=1.477$, $95 \%$ confidence interval $=1.049-7.172, p=0.04)$ and higher grading of the tumor (hazard ratio $=2.743,95 \%$ confidence interval $=0.049-7.172, p=0.004)$ proved to be independent prognostic factors for survival (Figure 2).

\section{Discussion}

Periampullary carcinomas are comprised of different tumor entities which are often difficult to discriminate in clinical practice. Nevertheless, most studies about prognostic factors focus on one tumor entity only and fail to compare the different entities occurring in the periampullary region.

In our cohort, patients suffering from PDAC, dCC and AC were all comparable as regards patient characteristics. In most previous studies, age and gender did not affect survival $(3,21$, 

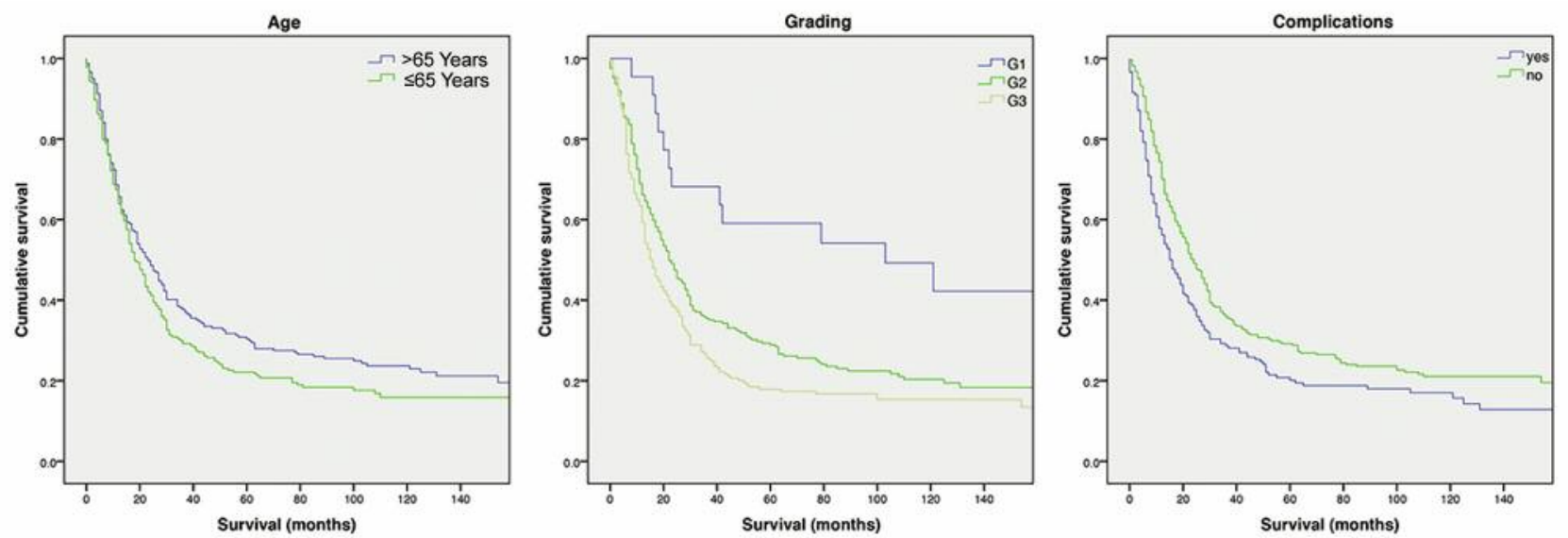

Figure 2. Kaplan-Meier curves of survival according to variables found to be significant in the multivariate analysis: Age, tumor grade and postoperative complications.

22). In our cohort, age ( $>65$ years) had a negative effect on long-term survival in multivariate analysis. This confirms the results of Futagawa et al. who identified age older than 75 years as a negative predictive factor for survival in 340 cases (23). However, older age was not correlated with an increased rate of postoperative complications in our cohort. On the contrary, a higher body mass index had a significant impact on survival in univariate analysis and was correlated with postoperative complications. Postoperative complications proved to have an effect on survival in the univariate and multivariate analyses.

The tumor size was significantly larger in patients suffering from PDAC. This might be due to the earlier onset of symptoms in patients with $\mathrm{dCC}$ and $\mathrm{AC}$ as jaundice usually occurs earlier in those patients (24). Patients with a tumor size smaller than 2 $\mathrm{cm}$ had a significantly longer survival in our cohort. This finding is consistent with current literature (24-27).

Comparing the three tumor entities, PDAC had the worst prognosis when compared to $\mathrm{dCC}$ and AC. Patient survival was consistent with that reported in other studies (24, 26-30). It is questionable if the impaired prognosis of the PDAC cohort was due to differences in tumor biology or based on delayed diagnosis. Schmidt et al. showed that the tumor entity is an independent factor influencing survival in a multivariate analysis of 516 cases, with poorest survival for patients suffering from PDAC (29). In addition, we found that patients with PDAC had a higher UICC stage at the time of operation. Patients with more advanced tumor stages are characterized by a significantly higher rate of LN metastasis in PDAC. In other words, more than two-thirds of patients with PDAC were nodal-positive, representing more aggressive tumor biological behavior.

Interestingly, the number of LN removed and the LNR did not differ between the entities but did have an effect on overall survival. In colon cancer, the LNR has been proven
Table IV. Variables showing a significant effect on the survival of patients in the univariate analysis.

\begin{tabular}{lcccr}
\hline Variable & \multicolumn{4}{c}{ Univariate analysis } \\
\cline { 3 - 5 } Cox regression & $\mathrm{n}$ & $\begin{array}{c}\text { Hazard } \\
\text { ratio }\end{array}$ & $95 \% \mathrm{CI}$ & $p$-Value \\
& \multicolumn{5}{c}{${ }^{2}$} \\
Age $>$ 65 Years & 471 & 1.016 & $1.005-1.027$ & 0.004 \\
CA 19-9 (ln) & 335 & 1.122 & $1.057-1.192$ & $<0.001$ \\
CEA $>37$ U7ml & 317 & 1.068 & $1.042-1.094$ & $<0.001$ \\
Duration of surgery $>340$ min & 407 & 1.002 & $1.000-1.004$ & $<0.001$ \\
Blood loss (ln) & 297 & 1.280 & $1.063-1.542$ & $<0.009$ \\
ICU stay >3 days & 359 & 1.011 & $1.003-1.020$ & 0.010 \\
Log-rank test & & & & $<0.001$ \\
Tumor entity & 472 & & & $<0.001$ \\
T-Stage & 471 & & & $<0.001$ \\
N-Stage & 471 & & & 0.001 \\
M-Stage & 471 & & & 0.001 \\
Resection & 463 & & & $<0.001$ \\
Grade & 467 & & & $<0.001$ \\
UICC stage & 471 & & & $<0.001$ \\
PPPD & 283 & & & 0.020 \\
Whipple & 176 & & & $<0.001$ \\
Postoperative complications & 454 & & \\
Operative revisions & 454 & & \\
\hline
\end{tabular}

CEA: Carcinoembryonic antigen; CA 19-9: carbohydrate antigen; CI: Confidence interval; ICU: Intensive Care Unit; PPPD: pyloruspreserving pancreaticoduodenectomy.

to be a relevant prognostic factor in representative patient cohorts (31). For this, attempts to include this variable in the classification of colon cancer have already been made (31). Corresponding findings have been described for PDAC (26). A study from Baltimore described LNR as one of the most powerful predictors of survival in a cohort of over 900 
patients (24). Similar results have been found in periampullary malignancies and in particular in $\mathrm{AC}$ where the LNR was found to be an independent prognostic factor after resection $(27,32,33)$. In our cohort, an increasing number of positive LNs as well as the LNR had a negative effect on overall survival, an increase of the LNR by $10 \%$ resulted in a survival decrease of $31 \%$. This highlights the relevance of $\mathrm{LN}$ dissection for accurate diagnostic staging.

Larger tumor size, a higher number of $\mathrm{R} 1$ resections, a higher rate of nodal and perineural invasion, a higher UICC stage and an overall worse prognosis of PDAC compared to $\mathrm{dCC}$ and $\mathrm{AC}$ raises the question if the one-size-fits-all treatment of periampullary cancer with resection up-front and adjuvant chemotherapy adequately address this aggressive tumor type. One important aspect that will shape this discussion is the increasing relevance of neoadjuvant chemotherapy. Whereas neoadjuvant treatment seems to be beneficial for locally advanced PDAC, evidence is still lacking for primary resectable PDAC, dCC and AC $(30,34)$. Different neoadjuvant regimens are usually applied in pancreatic cancer $(30,35-37)$. However, no randomized controlled trial has yet been completed. It is postulated that in the neoadjuvant setting, patients profit from early systemic control, which also helps discover those who will benefit from radical surgery and specific adjuvant regimens (36).

Reliable data for neoadjuvant treatment of periampullary cancer other than PDAC are scarce and less convincing (38, 39). To clarify whether patients with $\mathrm{dCC}$ or AC could nevertheless also benefit from this approach, prospective and treatment studies with exact discrimination between the tumor entities are needed.

\section{Conflicts of Interest and Funding}

None of the Authors has any conflict of interests to declare. Internal funding of the surgical clinic was used only. Dr. Rosa Schmuck is participant in the BIH-Charite Clinician Scientist Program funded by the Charité - Universitaetsmedizin Berlin and the Berlin Institute of Health.

\section{Acknowledgements}

The Authors thank all patients for their participation in the study. Moreover, we thank all nurses and physicians involved in the care of the patients.

\section{References}

1 Kimura W, Futakawa N and Zhao B: Neoplastic diseases of the papilla of Vater. J Hepatobiliary Pancreat Surg 11: 223-231, 2004.

2 Schmuck RB, de Carvalho-Fischer CV, Neumann C, Pratschke $\mathrm{J}$ and Bahra M: Distal bile duct carcinomas and pancreatic ductal adenocarcinomas: postulating a common tumor entity. Cancer Med 5: 88-99, 2016.
3 Riall TS, Cameron JL, Lillemoe KD, Winter JM, Campbell KA, Hruban RH, Chang D and Yeo CJ: Resected periampullary adenocarcinoma: 5-Year survivors and their 6-to 10-year followup. Surger 140: 764-772, 2006.

4 Yeo CJ, Sohn TA, Cameron JL, Hruban RH, Lillemoe KD and Pitt HA: Periampullary adenocarcinoma: analysis of 5-year survivors. Ann Surg 227: 821-831, 1998.

5 Geer RJ and Brennan MF: Prognostic indicators for survival after resection of pancreatic adenocarcinoma. Am J Surg 165: 68-72, 1993.

6 Yeo CJ, Cameron JL, Sohn TA, Lillemoe KD, Pitt HA, Talamini MA, Hruban RH, Ord SE, Sauter PK, Coleman J, Zahurak ML, Grochow LB and Abrams RA: Six hundred fifty consecutive pancreaticoduodenectomies in the 1990s: pathology, complications, and outcomes. Ann Surg 226: 248-257, 1997.

7 Jarnagin WR: Cholangiocarcinoma of the extrahepatic bile ducts. Semin Surg Oncol 19: 156-76, 2000.

8 Nakeeb A, Pitt HA, Sohn TA, Coleman J, Abrams RA, Piantadosi S, Hruban RH, Lillemoe KD, Yeo CJ and Cameron JL: Cholangiocarcinoma. A spectrum of intrahepatic, perihilar, and distal tumors. Ann Surg 224: 463-473, 1996

9 Talamini MA, Moesinger RC, Pitt HA, Sohn TA, Hruban RH, Lillemoe KD, Yeo CJ and Cameron JL: Adenocarcinoma of the ampulla of Vater. A 28-year experience. Ann Surg 225: 590-599, 1997.

10 Kimura W, Futakawa N, Yamagata S, Wada Y, Kuroda A, Muto $\mathrm{T}$ and Esaki $\mathrm{Y}$ : Different clinicopathologic findings in two histologic types of carcinoma of papilla of Vater. Jpn J Cancer Res 85: 161-166, 1994.

11 Okano K, Oshima M, Yachida S, Kushida Y, Kato K, Kamada H, Wato M, Nishihira T, Fukuda Y, Maeba T, Inoue H, Masaki $\mathrm{T}$ and Suzuki Y: Factors predicting survival and pathological subtype in patients with ampullary adenocarcinoma. J Surg Oncol 110: 156-162, 2014.

12 Chandrasegaram MD, Chen JW, Price TJ, Zalcberg J, Sjoquist $\mathrm{K}$ and Merrett ND: Advances in molecular pathology and treatment of periampullary cancers. Pancreas 45: 32-39, 2016.

13 Yachida S, Wood LD, Suzuki M, Takai E, Totoki Y, Kato M, Luchini C, Arai Y, Nakamura H, Hama N, Elzawahry A, Hosoda F, Shirota T, Morimoto N, Hori K, Funazaki J, Tanaka H, Morizane C, Okusaka T, Nara S, Shimada K and Hiraoka N: Genomic sequencing identifies ELF3 as a driver of ampullary carcinoma. Cancer Cell 29: 229-240, 2016.

14 Erdmann JI, Eskens FA, Vollmer CM, Kok NF, Groot Koerkamp $\mathrm{B}$, Biermann $\mathrm{K}$ and van Eijck $\mathrm{CH}$ : Histological and molecular subclassification of pancreatic and nonpancreatic periampullary cancers: Implications for (neo) adjuvant systemic treatment a. Ann Surg Oncol 22: 2401-2407, 2015.

15 National Comprehensive Cancer Network: Clinical Practice Guidelines in Oncology Pancreatic Adenocarcinoma, Second Edition. Basel, Karger, 2016.

16 Tang K, Lu W, Qin W and Wu Y: Neoadjuvant therapy for patients with borderline resectable pancreatic cancer: A systematic review and meta-analysis of response and resection percentages. Pancreatology 16: 28-37, 2016.

17 Eckardt AJ, Klein F, Adler A, Veltzke-Schlieker W, Warnick P, Bahra M, Wiedenmann B, Neuhaus P, Neumann K and Glanemann M: Management and outcomes of haemorrhage after pancreatogastrostomy versus pancreatojejunostomy. Br J Surg 98: 1599-607, 2011. 
18 Keck T, Wellner UF, Bahra M, Klein F, Sick O, Niedergethmann M, Wilhelm TJ, Farkas SA, Börner T, Bruns C, Kleespies A, Kleeff J, Mihaljevic AL, Uhl W, Chromik A, Fendrich V, Heeger K, Padberg W, Hecker A, Neumann UP, Junge K, Kalff JC, Glowka TR, Werner J, Knebel P, Piso P, Mayr M, Izbicki J, Vashist Y, Bronsert P, Bruckner T, Limprecht R, Diener MK, Rossion I, Wegener I and Hopt UT: Pancreatogastrostomy versus Pancreatojejunostomy for RECOnstruction After PANCreatoduodenectomy (RECOPANC, DRKS 00000767). Perioperative and long-term results of a multicenter randomized controlled trial. Ann Surg 263: 440-449, 2016.

19 Bassi C, Dervenis C, Butturini G, Fingerhut A, Yeo C, Izbicki J, Neoptolemos J, Sarr M, Traverso W, Buchler M, International Study Group on Pancreatic Fistula: Postoperative pancreatic fistula: An international study group (ISGPF) definition. Surgery 138: 8-13, 2005.

20 Committee on TNM Classification: TNM classification of malignant tumors, 20th Edition. International Union Against Cancer, Geneva, 2000.

21 Chen JW, Bhandari M, Astill DS, Wilson TG, Kow L, BrookeSmith M, Toouli J and Padbury RT: Predicting patient survival after pancreaticoduodenectomy for malignancy: Histopathological criteria based on perineural infiltration and lymphovascular invasion. HPB 12: 101-108, 2010.

22 Chen SC, Shyr YM and Wang SE: Long-term survival after pancreaticoduodenectomy for periampullary adenocarcinomas. HPB 15: 951-957, 2013.

23 Futagawa Y, Kanehira M, Furukawa K, Kitamura H, Yoshida S, Usuba T, Misawa T, Ishida Y, Okamoto T and Yanaga K: Study on the validity of pancreaticoduodenectomy in the elderly. Anticancer Res 37: 5309-5316, 2017.

24 Pawlik TM, Gleisner AL, Cameron JL, Winter JM, Assumpcao L, Lillemoe KD, Wolfgang C, Hruban RH, Schulick RD, Yeo CJ and Choti MA: Prognostic relevance of lymph node ratio following pancreaticoduodenectomy for pancreatic cancer. Surgery 141: 610-618, 2007.

25 Hatzaras I, George N, Muscarella P, Melvin WS, Ellison EC and Bloomston M: Predictors of survival in periampullary cancers following pancreaticoduodenectomy. Ann Surg Onco 17: 991-997, 2010.

26 Yamada S, Fujii T, Hirakawa A, Kanda M, Sugimoto H and Kodera Y: Lymph node ratio as parameter of regional lymph node involvement in pancreatic cancer. Langenbecks Arch Surg 401: 1143-1152, 2016.

27 Shamseddine AI, Mukherji D, Melki C, Elias E, Eloubeidi M, Dimassi H, Khalife M, Abou-Alfa G, O'Reilly E and Faraj W: Lymph node ratio is an independent prognostic factor after resection of periampullary malignancies: data from a tertiary referral center in the middle East. Am J Clin Oncol 37: 13-18, 2014.

28 Cho JY, Han HS, Yoon YS, Hwang DW, Jung K and Kim YK: Postoperative complications influence prognosis and recurrence patterns in periampullary cancer. World J Surg 37: 2234-2241, 2013.

29 Schmidt CM, Powell ES, Yiannoutsos CT, Howard TJ, Wiebke EA, Wiesenauer CA, Baumgardner JA, Cummings OW, Jacobson LE, Broadie TA, Canal DF, Goulet RJ Jr, Curie EA, Cardenes H, Watkins JM, Loehrer PJ, Lillemoe KD and Madura JA: Pancreaticoduodenectomy: a 20-year experience in 516 patients. Arch Surg 139: 718-25, 2004.

30 Turaga KK, Tsai S, Wiebe LA, Evans DB and Gamblin TC: Novel multimodality treatment sequencing for extrahepatic (mid and distal) cholangiocarcinoma. Ann Surg Oncol 20: 1230-1239, 2013.

31 Sugimoto K, Sakamoto K, Tomiki Y, Goto M, Kotake K and Sugihara K: Proposal of new classification for stage III colon cancer based on the lymph node ratio: analysis of 4,172 patients from multi-institutional database in Japan. Ann Surg Oncol 22: 528-534, 2015.

32 Falconi M, Crippa S, Domínguez I, Barugola G, Capelli P, Marcucci S, Beghelli S, Scarpa A, Bassi C and Pederzoli P: Prognostic relevance of lymph node ratio and number of resected nodes after curative resection of ampulla of Vater carcinoma. Ann Surg Oncol 15: 3178-3186, 2008.

33 Okabayashi T, Shima Y, Iwata J, Morita S, Sumiyoshi T, Sui K, Shimada Y and Iiyama T: Characterization of prognostic factors and the efficacy of adjuvant S-1 chemotherapy in patients with post-surgery extrahepatic bile duct cancer. Anticancer Res 37(12): 7049-7056, 2017.

34 Erdmann JI, Eskens FA, Vollmer CM, Kok NF, Groot Koerkamp $\mathrm{B}$, Biermann $\mathrm{K}$ and van Eijck $\mathrm{CH}$ : Histological and molecular subclassification of pancreatic and nonpancreatic periampullary cancers: Implications for (neo) adjuvant systemic treatment. Ann Surg Oncol 22: 2401-2407, 2015.

35 Louvet C, Labianca R, Hammel P, Lledo G, Zampino MG, André T, Zaniboni A, Ducreux M, Aitini E, Taïeb J, Faroux R, Lepere C, de Gramont A, GERCOR, GISCAD: Gemcitabine in combination with oxaliplatin compared with gemcitabine alone in locally advanced or metastatic pancreatic cancer: Results of a GERCOR and GISCAD phase III trial. J Clin Oncol 23: 3509-3516, 2005.

36 Faris JE, Blaszkowsky LS, McDermott S, Guimaraes AR, Szymonifka J, Huynh MA, Ferrone CR, Wargo JA, Allen JN, Dias LE, Kwak EL, Lillemoe KD, Thayer SP, Murphy JE, Zhu AX, Sahani DV, Wo JY, Clark JW, Fernandez-del Castillo C, Ryan DP and Hong TS: FOLFIRINOX in locally advanced pancreatic cancer: The Massachusetts General Hospital Cancer Center experience. Oncologist 18: 543-548, 2013.

37 Conroy T, Desseigne F, Ychou M, Bouché O, Guimbaud R, Bécouarn Y, Adenis A, Raoul JL, Gourgou-Bourgade S, de la Fouchardière C, Bennouna J, Bachet JB, Khemissa-Akouz F, PéréVergé D, Delbaldo C, Assenat E, Chauffert B, Michel P, MontotoGrillot C, Ducreux M, Groupe Tumeurs Digestives of Unicancer and PRODIGE Intergroup: FOLFIRINOX versus gemcitabine for metastatic pancreatic cancer. N Engl J Med 364: 1817-1825, 2011.

38 Klinkenbijl JH, Jeekel J and Sahmoud T: Adjuvant radiotherapy and 5-fluorouracil after curative resection of cancer of the pancreas and periampullary region: Phase III trial of the EORTC Gastrointestinal Tract Cancer Cooperative Group. Ann Surg 230: 776-782, 1999.

39 Neoptolemos JP, Moore MJ, Cox TF, Valle JW, Palmer DH, McDonald AC, Carter R, Tebbutt NC, Dervenis C, Smith D, Glimelius B, Charnley RM, Lacaine F, Scarfe AG, Middleton MR, Anthoney A, Ghaneh P, Halloran CM, Lerch MM, Oláh A, Rawcliffe CL, Verbeke CS, Campbell F, Büchler MW and European Study Group for Pancreatic Cancer: Effect of adjuvant chemotherapy with fluorouracil plus folinic acid or gemcitabine $v s$. observation on survival in patients with resected periampullary adenocarcinoma: The ESPAC-3 periampullary cancer randomized trial. JAMA 308: 147-156, 2012.

Received July 12, 2018

Revised August 15, 2018 Accepted August 23, 2018 